\title{
Tests of conspecificity for allopatric vectors: Simulium nodosum and Simulium shirakii (Diptera: Simuliidae) in Asia
}

\author{
Van Lun Low ${ }^{1 *}$, Peter H. Adler ${ }^{2 *}$, Mohd Sofian-Azirun ${ }^{1}$, Wichai Srisuka ${ }^{3,4}$, Atiporn Saeung ${ }^{4}$, Yao-Te Huang ${ }^{5}$,
} Upik Kesumawati Hadi ${ }^{6}$, Xuan Da Pham ${ }^{7}$ and Hiroyuki Takaoka ${ }^{1}$

\begin{abstract}
Background: Allopatric populations present challenges for biologists working with vectors. We suggest that conspecificity can be concluded in these cases when data from four character sets-chromosomal, ecological, molecular, and morphological-express variation no greater between the allopatric populations than between corresponding sympatric populations. We use this approach to test the conspecificity of Simulium nodosum Puri on the mainland of Southeast Asia and Simulium shirakii Kono \& Takahasi in Taiwan. The validity of these two putative species has long been disputed given that they are morphologically indistinguishable.

Findings: The mitochondria-encoded cytochrome c oxidase subunit I (COI), 12S rRNA, and 16S rRNA genes and the nuclear-encoded $28 \mathrm{~S}$ rRNA gene support the conspecific status of S. nodosum from Myanmar, Thailand, and Vietnam and S. shirakii from Taiwan; 0 to $0.19 \%$ genetic differences between the two taxa suggest intraspecific polymorphism. The banding patterns of the polytene chromosomes of the insular Taiwanese population of S. shirakii and mainland populations of $S$. nodosum are congruent. The overlapping ranges of habitat characteristics and hosts of $S$. nodosum and S. shirakii corroborate the chromosomal, molecular, and morphological data.

Conclusions: Four independent sources of evidence (chromosomes, DNA, ecology, and morphology) support the conspecificity of S. nodosum and S. shirakii. We, therefore, synonymize S. shirakii with S. nodosum. This study provides a guide for applying the procedure of testing conspecificity to other sets of allopatric vectors.
\end{abstract}

Keywords: Simulium nobile species group, Black flies, Phylogeny, Polytene chromosomes, Systematics, Multi-locus, Conspecificity

\section{Background}

Simuliid vectors of human and animal pathogens typically are complexes of evolutionarily and ecologically distinct cryptic species, for which accurate identification is an essential first step in the epidemiological understanding and control of arthropod-borne diseases [1-4]. Compounding the challenge of recognizing cryptic species is the difficulty of evaluating the species status of allopatric populations. The problem is particularly acute when populations are widely disjunct on the mainland, between mainlands, or between an island and the mainland [5].

\footnotetext{
*Correspondence: lucaslow24@gmail.com; padler@clemson.edu

${ }^{1}$ Institute of Biological Sciences, Faculty of Science, University of Malaya,

Kuala Lumpur, Malaysia

${ }^{2}$ Department of Agricultural and Environmental Sciences, Clemson University, Clemson, SC, USA

Full list of author information is available at the end of the article
}

Assigning the same or different names to allopatric populations has consequences for understanding vector potential and developing control strategies [6].

A classic example of the challenge of evaluating species status for allopatric populations involves Simulium nodosum Puri, distributed from India across southern China, Myanmar, Thailand, and Vietnam [7], and the morphologically similar Simulium shirakii Kono \& Takahasi from Taiwan, more than $130 \mathrm{~km}$ from the Chinese mainland. Although S. shirakii has been treated for 80 years as a separate species, its species status has long been questioned because of morphological similarity with S. nodosum [8]. Simulium nodosum is mammalophilic, attacking humans and bovids [9-11]. It is also a vector of the agents of filariasis to ruminants [10]. 
Although allopatry confounds the evaluation of reproductive isolation, we suggest that allopatric populations, including putative species, can be considered conspecific when differences in their molecular sequences, chromosomal profiles, morphology, and ecology are within the range of variation for a geographically cohesive, panmictic set of populations. All four character sources require evaluation, given the existence of homosequential sibling species [12] and the failure of up to three of the character sets to discriminate reproductively isolated sympatric species [13].

We applied this test to two members of the Simulium nobile species group, S. nodosum and S. shirakii. The detailed morphological comparisons by Takaoka \& Suzuki [8] between S. nodosum and S. shirakii originally suggested conspecificity and prompted the present study. We used a multi-locus phylogenetic analysis of one nuclear and three mitochondrial genes, a comparative analysis of the polytene chromosomes, and an evaluation of ecological data associated with our collections and in the literature $[9,14-16]$.

\section{Methods}

No national permissions were required for this study, which did not involve endangered or protected species. No specific permissions were required to access the study sites; the collections were made on public lands.

Larvae were collected by hand into ethanol from five sites in Myanmar, Taiwan, Thailand, and Vietnam (Table 1). Additional samples of larvae from Taiwan were collected into 1:3 acetic ethanol for chromosomal comparison with published information [15]. Habitat characteristics at each collection site were recorded, including altitude, canopy cover, and stream depth, temperature, and width. Species identifications were performed using illustrated taxonomic keys $[8,14,17-19]$.

The nucleotide sequences of the mitochondriaencoded COI, 12S rRNA, and 16S rRNA genes and the nuclear-encoded $28 \mathrm{~S}$ rRNA gene were used. These genetic markers have been used to differentiate other simuliid species [20-23]. In addition to $S$. nodosum and $S$. shirakii, we included two nominal members of the $S$. nobile species group-Simulium nobile De Meijere from Gombak, Selangor, Malaysia (collected 23/07/14) and Simulium timorense Takaoka, Hadi \& Sigit from Kupang, Timor Island, Indonesia (collected 27/02/14) - for phylogenetic analysis.

Genomic DNA was extracted from each of five specimens per location, using the i-genomic CTB DNA Extraction Mini Kit (iNtRON Biotechnology Inc., Seongnam, South Korea). Amplifications of the mitochondriaencoded COI, 12S rRNA, and 16S rRNA, and nuclearencoded $28 \mathrm{~S}$ rRNA genes were undertaken in a final volume of $50 \mu \mathrm{L}$ containing 50-100 ng genomic DNA, $25 \mu \mathrm{L}$ of ExPrime Taq Master Mix (GENETBIO Inc., Daejeon, South Korea), and 10 pmol of each forward and reverse primer. The primers used in this study were adopted from Folmer et al. [24] for COI, Kocher et al. [25] and Simon et al. [26] for $12 \mathrm{~S}$ rRNA, Xiong \& Kocher [20] for $16 \mathrm{~S}$ rRNA, and Low et al. [27] for $28 \mathrm{~S}$ rRNA.

Data on the nucleotide sequences of the COI, $12 \mathrm{~S}$ rRNA, 16S rRNA, and 28S rRNA genes were deposited in the NCBI GenBank under accession numbers KP661441-KP661560. DNA sequences were analysed and edited using ChromasPro 1.5 (Technelysium Pty Ltd, Brisbane, Qld, Australia) and BioEdit 7.0.9.0. [28]. Statistical congruence was calculated using a partition homogeneity test implemented in PAUP 4.0b10 [29]. No significant differences were found among separate gene regions $(P=0.600)$; hence, data were concatenated for further analyses (Fig. 1 and Table 2). Aligned sequences of single genes and the concatenated dataset were subjected to Bayesian inference (BI) analysis using MrBayes 3.1.2 [30], neighbour-joining (NJ) and maximum parsimony (MP) analyses using PAUP 4.0b10, and maximum likelihood (ML) analysis using Treefinder Version October 2008 [31]. Simulium tani Takaoka \& Davies cytoform 'K' and Simulium leparense Takaoka, Sofian-Azirun \& Ya'cob were used as outgroups. To determine intra- and interspecific variation among species/population pairs, uncorrected $(p)$ pairwise genetic distances were calculated using PAUP 4.0B10.

We used the Feulgen technique and chromosomal slide-mounting procedures outlined by Adler et al. [32] to prepare the polytene chromosomes of 51 larvae from two sites (19 larvae from Guangfu, 32 larvae from Ruisui) in Taiwan (Table 1). Larval carcasses were deposited in the Clemson University Arthropod Collection. The chromosomes of all 51 larvae ( 25 females, 26 males) were compared band-for-band with the standard map for the subgenus Simulium [33, 34] and with the chromosomes of larvae analyzed by Tangkawanit et al. [15] from nine sites in Thailand.

\section{Findings}

The phylogenetic tree for the concatenated dataset comprised two main clusters (Fig. 1). One cluster, consisting of S. nobile and S. timorense, was supported with full posterior probability/bootstrap values $(\mathrm{BI}=1.00, \mathrm{NJ}=$ $100 \%, \mathrm{MP}=100 \%, \mathrm{ML}=100 \%)$. The other cluster, consisting of S. nodosum and S. shirakii from different geographical regions, was supported with high to full posterior probability/bootstrap values $(\mathrm{BI}=0.99, \mathrm{NJ}=$ $100 \%, \mathrm{MP}=100 \%, \mathrm{ML}=100 \%$ ).

No phylogenetic tree from the concatenated dataset nor the single-locus analyses separated $S$. nodosum from S. shirakii. Both putative species were distributed randomly in the trees (Additional file 1: Figures S1-S4). The 
Table 1 Collection data for populations used in chromosomal and molecular analyses of Simulium nodosum and S. shirakii

\begin{tabular}{|c|c|c|c|c|c|c|c|c|}
\hline Locality & Coordinates & Date & Taxon & Altitude & Width & Depth & Temperature & Canopy cover \\
\hline \multirow[t]{2}{*}{ San Village, Chiang-Tung, Myanmar } & $21^{\circ} 05^{\prime} 18.5^{\prime \prime} \mathrm{N}$ & $27 / 10 / 2013$ & S. nodosum & $958 \mathrm{~m}$ & $50 \mathrm{~m}$ & $20 \mathrm{~cm}$ & $22.7^{\circ} \mathrm{C}$ & Open \\
\hline & $99^{\circ} 47^{\prime} 39.7^{\prime \prime} \mathrm{E}$ & & & & & & & \\
\hline \multirow[t]{2}{*}{ Da Chais, Lam Dong, Vietnam } & $12^{\circ} 08^{\prime} 32.4^{\prime \prime} \mathrm{N}$ & $24 / 04 / 2014$ & S. nodosum & $1439 \mathrm{~m}$ & $3-6 m$ & NA & $20.0^{\circ} \mathrm{C}$ & Open \\
\hline & $108^{\circ} 38^{\prime} 58.3^{\prime \prime} \mathrm{E}$ & & & & & & & \\
\hline \multirow[t]{2}{*}{ Doi Saket, Chiang Mai, Thailand } & $19^{\circ} 02^{\prime} 27.2^{\prime \prime} \mathrm{N}$ & $24 / 08 / 2014$ & S. nodosum & $733 \mathrm{~m}$ & $3.5 \mathrm{~m}$ & $35 \mathrm{~cm}$ & $22.7^{\circ} \mathrm{C}$ & Open \\
\hline & $99^{\circ} 20^{\prime} 06.0^{\prime \prime} \mathrm{E}$ & & & & & & & \\
\hline \multirow[t]{2}{*}{ Guangfu, Hualien, Taiwan } & $23^{\circ} 31^{\prime} 12.7^{\prime \prime} \mathrm{N}$ & $24 / 11 / 2008$ & S. shirakii & $70 \mathrm{~m}$ & $1 \mathrm{~m}$ & NA & $22.0^{\circ} \mathrm{C}$ & Shaded \\
\hline & $121^{\circ} 24^{\prime} 44.5^{\prime \prime} \mathrm{E}$ & & & & & & & \\
\hline \multirow[t]{2}{*}{ Ruisui, Hualien, Taiwan } & $23^{\circ} 38^{\prime} 11.9^{\prime \prime} \mathrm{N}$ & $25 / 11 / 2008$ & S. shirakii & $15 \mathrm{~m}$ & $15 \mathrm{~m}$ & NA & $22.0^{\circ} \mathrm{C}$ & Open \\
\hline & $121^{\circ} 25^{\prime} 17.8^{\prime \prime} \mathrm{E}$ & & & & & & & \\
\hline
\end{tabular}

NA not available

pairwise genetic distance analysis revealed intraspecific variation ranging from 0 to $0.23 \%$ for $S$. nodosum from Vietnam, Myanmar, and Thailand; 0 to $0.08 \%$ for $S$. shirakii from Taiwan; and 0 to $0.19 \%$ for $S$. nodosum $/ S$. shirakii (Table 2). The interspecific variation between $S$. nodosum/S. shirakii and S. nobile, and between S. nodosum/S. shirakii and S. timorense, ranged from 5.10 to $5.45 \%$ and 5.18 to $5.45 \%$, respectively. Thus, the level of polymorphism (0-0.19\%) between $S$. nodosum and $S$. shirakii was less than that between all pairs of mainland populations and within the Myanmar population (0.04$0.23 \%$ ) and far below that of $S$. nobile or S. timorense.

Chromosomal banding patterns of all Taiwanese larvae were four fixed inversions (IS-1, IIL- $a$, IIIL- $b$, IIIL-2) removed from the Simulium subgeneric standard sequence, and matched the fixed banding sequence of all 247 Thai larvae studied by Tangkawanit et al. [14]. Taiwanese and Thai populations had the nucleolar organizer in the end of IIS, undifferentiated sex chromosomes, and only two autosomal polymorphisms each, one of which (IIIL-1) was shared. The frequency of IIIL-1 was 0.99-nearly fixed-in Taiwan, and an average of 0.28 in Thai populations analyzed by Tangkawanit et al. [15]. The chromosome map of Tangkawanit et al. [15] for IIIL, however, shows the homozygous sequence for the IIIL-1 inversion rather than the claimed standard sequence; in addition, the distal breakpoint is shown as extended by one band beyond the actual breakpoint. IIL-1 was an infrequent inversion (average frequency $=0.04$ ) in Thailand [15] and absent in Taiwan. IL-1 was a new, but rare (0.01) inversion, with breakpoints before the last bands in each of sections 39 and 40, in one male larva in Taiwan. Ectopic pairing of centromeres formed a loose pseudochromocenter in populations in Thailand [15] but was present in only about $1 \%$ of nuclei per larva in Taiwan.

Habitat characteristics for our collection sites of $S$. nodosum and S. shirakii, such as stream width, overlapped broadly. Altitude, however, was considerably greater for our mainland populations $(733-1439 \mathrm{~m})$ than for our Taiwanese populations (15-70 m) (Table 1).

\section{Discussion}

All four data sources-molecular, chromosomal, morphological, and ecological-independently support the conspecificity of S. nodosum and S. shirakii across a longitudinal range of $2365 \mathrm{~km}$, providing a powerful consensus that $S$. shirakii and mainland populations in Myanmar, Thailand, and Vietnam are a single species. Our multi-locus analysis demonstrates that genetic differences within mainland populations of S. nodosum are greater than the differences between $S$. nodosum collectively and S. shirakii.

Simulium nodosum from Thailand and S. shirakii from Taiwan are identical in all details of their fixed chromosomal inversions and sex chromosomes, and share one of three autosomal inversions, the other two being rare. Inversion IIIL-1, which is found in about one-third of all homologues of Thai larvae and is nearly fixed in Taiwanese larvae, possibly expresses clinal variation, with lowest polymorphism in the Taiwan population, a common characteristic of insular and peripheral populations [32].

Habitat characteristics that typically differ between closely related species, especially stream size [35], are broadly overlapping among populations from Taiwan and the mainland, in agreement with records from the literature [14, 15]. Known hosts, which can differ between closely related species [36], are consistent (bovids and humans) across the distribution [9, 11, 14]. Altitude, however, which can be associated with genetic isolation [37], differs between our populations in Taiwan $(15-70 \mathrm{~m})$ and on the mainland (733-1439 $\mathrm{m})$. The altitudinal distinction, however, narrows or disappears when we draw from published information [14], suggesting that some of the discrepancy is attributable to sampling artifact. Elevation for S. nodosum in Thailand, for instance, ranged from 168 to $800 \mathrm{~m} \mathrm{[15]}$. The available ecological data suggest that a 


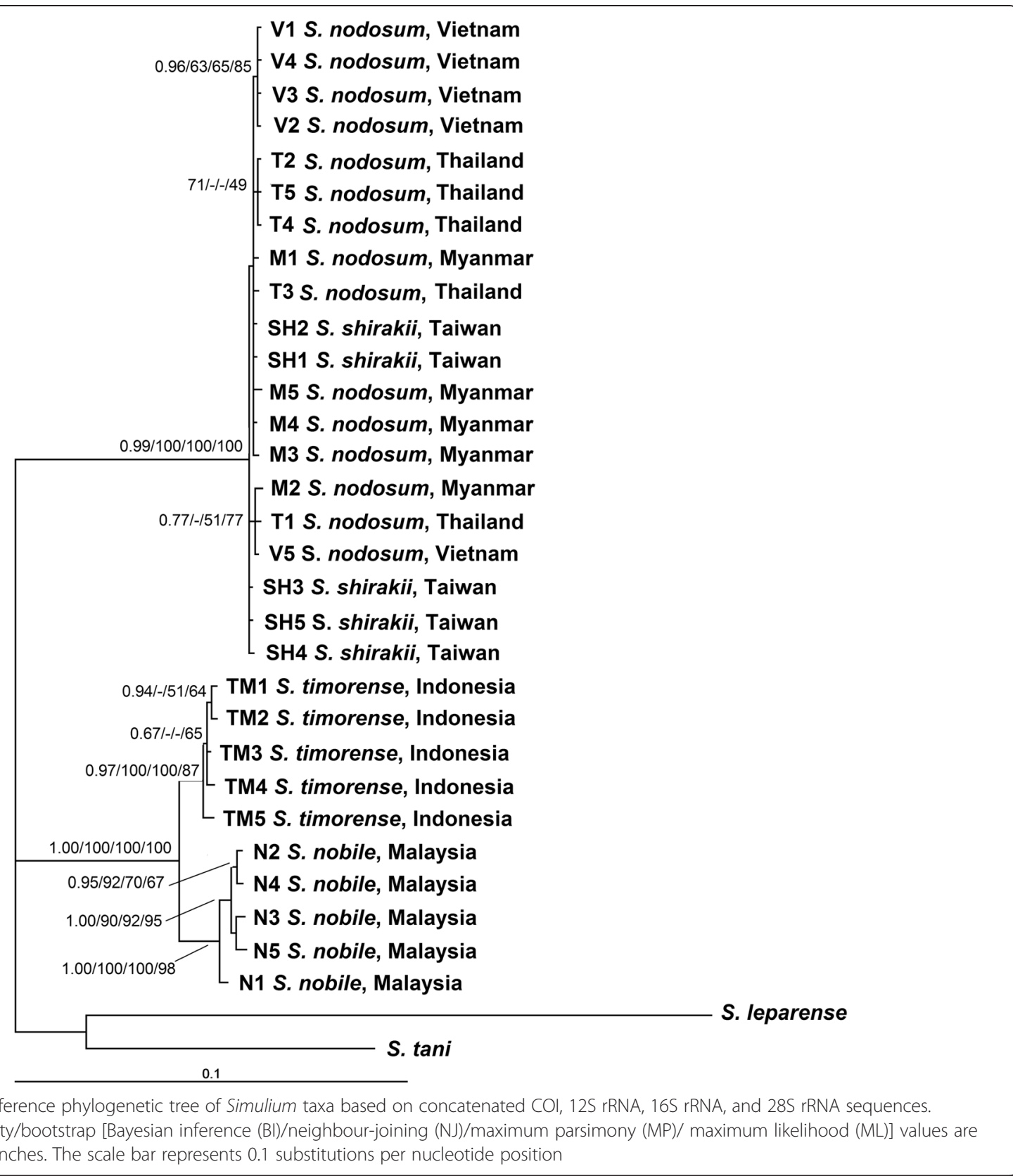

Table 2 Ranges of intra- and interspecific genetic distances (uncorrected p, expressed as percentages) based on concatenated COI, 125 rRNA, 165 rRNA, and $28 \mathrm{~S}$ rRNA sequences

\begin{tabular}{llllll}
\hline & 1 & 2 & 3 & 4 & 5 \\
\hline 1. S. nodosum (Myanmar) & $0.04-0.23$ & & & & \\
2. S. nodosum (Vietnam) & $0.04-0.23$ & $0.00-0.15$ & & & \\
3. S. nodosum (Thailand) & $0.04-0.23$ & $0.04-0.19$ & $0.00-0.19$ & & \\
4. S. shirakii (Taiwan) & $0.00-0.19$ & $0.04-0.12$ & $0.04-0.15$ & $0.00-0.08$ & $0.08-0.35$ \\
5. S. nobile & $5.18-5.41$ & $5.22-5.41$ & $5.14-5.45$ & $5.10-5.37$ & $1.00-1.27$ \\
6. S. timorense & $5.22-5.41$ & $5.29-5.41$ & $5.26-5.45$ & $5.18-5.37$ & $0.04-0.23$ \\
\hline
\end{tabular}


broad range of habitat conditions is typical for S. nodosum and S. shirakii. Insular populations, in particular, are more likely to have a broader ecological niche, resulting in part from ecological release [38].

The molecular separation of $S$. nodosum and S. shirakii from S. nobile and S. timorense is in concordance with their morphological characters. The simple claws of the females and the number and form of the pupal gill filaments (three inflated horn-like tubes) separate $S$. nodosum/S. shirakii from other members of the $S$. nobile species group [8].

\section{Conclusions}

Given the conspecificity of S. shirakii with mainland populations, what taxonomic decision should be applied to populations across the entire range of S. nodosum and S. shirakii, from the type locality in India to Taiwan? Attempts by colleagues from India to collect $S$. nodosum from its type locality, approximately $2500 \mathrm{~km}$ from our nearest site of analysis (Thailand), did not produce $S$. nodosum. Lacking topotypical material for molecular and chromosomal analyses, we acknowledge two alternative possibilities: (1) recognition of two species-S. nodosum, represented by the type from India, and S. shirakii, represented by the material in our study, from Myanmar to Taiwan, or (2) recognition of a single species, S. nodosum, across the full range from India to Taiwan. We provisionally select the latter option on pragmatic grounds; the same name, when applied across the entire range, holds greater information content, emphasizing the morphological and ecological similarity of all populations. We, therefore, synonymize $S$. shirakii with S. nodosum.

\section{Additional file}

Additional file 1: Figure S1. Bayesian inference phylogenetic tree of Simulium taxa based on COI sequences. Posterior probability/bootstrap [Bayesian inference (BI)/neighbour-joining (NJ)/maximum parsimony (MP)/ maximum likelihood (ML)] values are shown on the branches. The scale bar represents 0.1 substitutions per nucleotide position. Figure S2. Bayesian inference phylogenetic tree of Simulium taxa based on 125 rRNA sequences. Posterior probability/bootstrap [Bayesian inference (BI)/ neighbour-joining (NJ)/maximum parsimony (MP)/ maximum likelihood $(\mathrm{ML})]$ values are shown on the branches. The scale bar represents 0.1 substitutions per nucleotide position. Figure S3. Bayesian inference phylogenetic tree of Simulium taxa based on 165 rRNA sequences. Posterior probability/bootstrap [Bayesian inference (BI)/neighbour-joining $(\mathrm{NJ})$ /maximum parsimony (MP)/ maximum likelihood (ML)] values are shown on the branches. The scale bar represents 0.1 substitutions per nucleotide position. Figure $\mathbf{S} 4$. Bayesian inference phylogenetic tree of Simulium taxa based on 285 rRNA sequences. Posterior probability/bootstrap [Bayesian inference (BI)/neighbour-joining (NJ)/maximum parsimony (MP)/ maximum likelihood (ML)] values are shown on the branches. The scale bar represents 0.1 substitutions per nucleotide position.

\section{Competing interests}

The authors declare that they have no competing interests.

\section{Authors' contributions}

VLL, PHA, MSA and HT contributed to the study design. MSA, WS, AS, YTH, UKH, XDP and HT contributed to specimen collection. VLL and PHA performed the experimental work. VLL and PHA analysed the data. VLL and PHA wrote the manuscript. All authors read and approved the final manuscript.

\section{Acknowledgments}

This study was financially supported by research grants from the University of Malaya (RP003C-13SUS and RP003A-13SUS) and the Fundamental Research Grant Scheme (FP016-2012A).

\section{Author details}

${ }^{1}$ Institute of Biological Sciences, Faculty of Science, University of Malaya, Kuala Lumpur, Malaysia. ${ }^{2}$ Department of Agricultural and Environmental Sciences, Clemson University, Clemson, SC, USA. ${ }^{3}$ Entomology Section, Queen Sirikit Botanic Garden, Chiang Mai, Thailand. ${ }^{4}$ Department of Parasitology, Faculty of Medicine, Chiang Mai University, Chiang Mai, Thailand. ${ }^{5}$ Fuji Environmental Service, Mitsuwa, Kawaguchi City, Saitama, Japan. ${ }^{6}$ Department of Animal Infectious Diseases and Veterinary Public Health, Faculty of Veterinary Medicine, Bogor Agricultural University, Bogor, Indonesia. ${ }^{7}$ National Institute of Food Control, Ministry of Health, Hanoi, Vietnam.

Received: 7 April 2015 Accepted: 20 May 2015

Published online: 29 May 2015

\section{References}

1. Post RJ, Cheke RA, Boakye DA, Wilson MD, Osei-Atweneboana MY, Tetteh-Kumah A, et al. Stability and change in the distribution of cytospecies of the Simulium damnosum complex (Diptera: Simuliidae) in southern Ghana from 1971 to 2011. Parasit Vectors. 2013;13(6):205.

2. Procunier WS. Cytological approaches to simuliid biosystematics in relation to the epidemiology and control of human onchocerciasis. Genome. 1989:32(4):559-69.

3. Post RJ, Mustapha M, Krueger A. Taxonomy and inventory of the cytospecies and cytotypes of the Simulium damnosum complex (Diptera: Simuliidae) in relation to onchocerciasis. Trop Med Int Health 2007;12(11):1342-53.

4. Adler PH, Cheke RA, Post RJ. Evolution, epidemiology, and population genetics of black flies (Diptera: Simuliidae). Infect Genet Evol. 2010;10(7):846-65.

5. Adler PH, Giberson DJ, Purcell LA. Insular black flies (Diptera: Simuliidae) of North America: tests of colonization hypotheses. J Biogeogr. 2005;32(2):211-20.

6. Adler PH. Biodiversity of biting flies: implications for humanity. In: Foottit RG, Adler PH, editors. Insect biodiversity: science and society. Chichester: Wiley-Blackwell Publishing; 2009. p. 523-45.

7. Adler PH, Crosskey RW. World blackflies (Diptera: Simuliidae): a comprehensive revision of the taxonomic and geographical inventory. 2015, http://www.clemson.edu/cafls/biomia/pdfs/blackflyinventory.pdf. Accessed 26 Mar 2015.

8. Takaoka H, Suzuki H. The black flies from Thailand (Diptera: Simuliidae). Jap J Sanit Zool. 1984:35(1):7-45.

9. Datta M. An overview of the Simuliidae (Diptera) of West Bengal. India J Bengal Nat Hist Soc. 1992;11:41-62.

10. Takaoka H, Choochote W, Aoki C, Fukuda M, Bain O. Black flies (Diptera: Simuliidae) attracted to humans and water buffalos and natural infections with filarial larvae, probably Onchocerca sp., in northern Thailand. Parasite. 2003;10(1):3-8.

11. Choochote W, Takaoka H, Fukuda M, Otsuka Y, Aoki C, Eshima N. Seasonal abundance and daily flying activity of black flies (Diptera: Simuliidae) attracted to human baits in Doi Inthanon National Park, northern Thailand. Med Entomol Zool. 2005;56(4):335-48

12. Henderson CAP. Homosequential species $2 a$ and $2 b$ within the Prosimulium onychodactylum complex (Diptera): temporal heterogeneity, linkage disequilibrium, and Wahlund effect. Can J Zool. 1986:64(4):859-66.

13. Ilmonen J, Adler PH, Malmqvist B, Cywinska A. The Simulium vernum group (Diptera: Simuliidae) in Europe: multiple character sets for assessing species status. Zool J Linn Soc. 2009;156(4):847-63.

14. Takaoka H. The black flies of Taiwan (Diptera: Simuliidae). Pac Insect. 1979;20(4):365-403. 
15. Tangkawanit U, Kuvangkadilok C, Trinachartvanit W, Baimai V. Cytotaxonomy, morphology, and ecology of the Simulium nobile species group (Diptera: Simuliidae) in Thailand. Cytogenet Genome Res. 2011;134(4):308-18.

16. Datta M. Note on the evolution of Simulium asishi Datta from Simulium nodosum Puri (Diptera: Simuliidae) in West Bengal. India Proc Zool Soc (Calcutta). 1992;45:123-7.

17. Puri IM. Studies on Indian Simuliidae. Part VII. Descriptions of larva, pupa and female of Simulium nodosum sp. nov., with an appendix dealing with S. novolineatum nov. nom. (= S. lineatum Puri). Ind J Med Res. 1933;20(3):813-7.

18. Takaoka H, Davies DM. The black flies (Diptera: Simuliidae) of Java, Indonesia. Bishop Museum Bulletin in Entomology 6. Honolulu: Bishop Museum Press; 1996.

19. Takaoka H, Hadi UK, Sigit SH. The black flies (Diptera: Simuliidae) of Flores and Timor. Indonesia Med Entomol Zool. 2006;57(1):1-26.

20. Xiong B, Kocher TD. Comparison of mitochondrial DNA sequences of seven morphospecies of black flies (Diptera: Simuliidae). Genome. 1991;34(2):306-11.

21. Phayuhasena S, Colgan DJ, Kuvangkadilok C, Pramual P, Baimai V. Phylogenetic relationships among the black fly species (Diptera: Simuliidae) of Thailand based on multiple gene sequences. Genetica. 2010;138(6):633-48.

22. Conflitti IM, Spironello M, Currie DC. Molecular phylogeny of the North American Simulium malyschevi-group species (Diptera: Simuliidae). Syst Entomol. 2012;37(3):571-7.

23. Low VL, Takaoka H, Adler PH, Ya'cob Z, Norma-Rashid Y, Chen CD, et al. A multi-locus approach resolves the phylogenetic relationships of the Simulium asakoae and Simulium ceylonicum species groups (Diptera: Simuliidae) in Malaysia: evidence for distinct evolutionary lineages. Med Vet Entomol. doi: 10.1111/mve.12120.

24. Folmer O, Black M, Hoeh W, Lutz R, Vrijenhoek R. DNA primers for amplification of mitochondrial cytochrome c oxidase subunit I from diverse metazoan invertebrates. Mol Mar Biol Biotechnol. 1994;3(5):294-9.

25. Kocher TD, Thomas WK, Meyer A, Edwards SV, Pääbo S, Villablanca FX, et al. Dynamics of mitochondrial DNA evolution in animals: amplification and sequencing with conserved primers. Proc Natl Acad Sci U S A. 1989;86(16):6196-200.

26. Simon C, Frati F, Beckenbach A, Crespi B, Liu H, Flook P. Evolution, weighting, and phylogenetic utility of mitochondrial gene sequences and a compilation of conserved polymerase chain reaction primers. Ann Entomol Soc Am. 1994;87(6):651-701.

27. Low VL, Adler PH, Takaoka H, Ya'cob Z, Lim PE, Tan TK, et al. Mitochondrial DNA markers reveal high genetic diversity but low genetic differentiation in the black fly Simulium tani Takaoka \& Davies along an elevational gradient in Malaysia. PLoS One. 2014;9(6):e100512.

28. Hall TA. BioEdit: a user-friendly biological sequence alignment editor and analysis program for Windows 95/98/NT. Nucleic Acids Symp Ser. 1999:41:95-8.

29. Swofford DL. PAUP*. Phylogenetic Analysis Using Parsimony ( ${ }^{*}$ and other Methods). USA: Sinauer Associates; 2002.

30. Huelsenbeck JP, Ronquist F. MRBAYES: Bayesian inference of phylogenetic trees. Bioinformatics. 2001;17(8):754-5.

31. Jobb G, von Haeseler A, Strimmer K. Treefinder: a powerful graphical analysis environment for molecular phylogenetics. BMC Evol Biol. 2004;4:18.

32. Adler PH, Huang YT, Reeves WK, Kim SK, Otsuka Y, Takaoka H. Macrogenomic evidence for the origin of the black fly Simulium suzukii (Diptera: Simuliidae) on Okinawa Island, Japan. PLoS One. 2013;8(8):1-13.

33. Rothfels K, Feraday R, Kaneps A. A cytological description of sibling species of Simulium venustum and S. verecundum with standard maps for the subgenus Simulium Davies [sic] (Diptera). Can J Zool. 1978;56(5):1110-28.

34. Tangkawanit U, Kuvangkadilok C, Baimai V, Adler PH. Cytosystematics of the Simulium tuberosum group (Diptera: Simuliidae) in Thailand. Zool J Linn Soc. 2009;155(2):289-315.

35. Adler PH. Ecology of black fly sibling species. In: Kim KC, Merritt RW, editors. Black flies: ecology, population management and annotated world list. Pennsylvania: Pennsylvania State University Press; 1988. p. 63-76.

36. Krueger A. Zoophily and animal filariae in Simulium damnosum s.l.: on the indicative property of tarsal claws in females. Acta Entomol Serbica. 2006:206(Suppl):39-50.

37. Pramual P, Pangjanda S. Effects of habitat specialization on population genetic structure of black fly Simulium weji Takaoka (Diptera: Simuliidae). J Asia-Pacific Entomol. 2015;18(1):33-7.

38. Osborne PL. Tropical ecosystems and ecological concepts. 2nd ed. New York: Cambridge University Press; 2007.

\section{Submit your next manuscript to BioMed Central and take full advantage of:}

- Convenient online submission

- Thorough peer review

- No space constraints or color figure charges

- Immediate publication on acceptance

- Inclusion in PubMed, CAS, Scopus and Google Scholar

- Research which is freely available for redistribution

Submit your manuscript at www.biomedcentral.com/submit 